\title{
Reference Correction: Video-Delivered Family Therapy for Home Visited Young Mothers With Perinatal Depressive Symptoms: Quasi-Experimental Implementation-Effectiveness Hybrid Trial
}

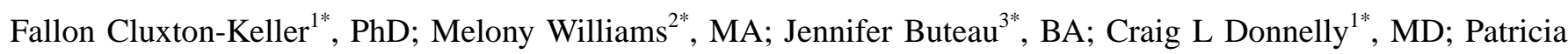
Stolte $^{3 *}$, BS; Maggie Monroe-Casse ${ }^{2 *}$, BA, MDiv; Martha L Bruce ${ }^{1 *}, \mathrm{MPH}, \mathrm{PhD}$

${ }^{1}$ Department of Psychiatry, Geisel School of Medicine at Dartmouth College, Lebanon, NH, United States

${ }^{2}$ FRC, Claremont, NH, United States

${ }^{3}$ FRC, Gorham, NH, United States

*all authors contributed equally

Corresponding Author:

Fallon Cluxton-Keller, $\mathrm{PhD}$

Department of Psychiatry

Geisel School of Medicine at Dartmouth College

1 Medical Center Drive

Lebanon, NH, 03756

United States

Phone: 16036504724

Email: Fallon.P.Cluxton-Keller@ dartmouth.edu

\section{Related Article:}

Correction of: https://mental.jmir.org/2018/4/e11513/

(JMIR Ment Health 2019;6(9):e15661) doi: 10.2196/15661

In "Video-Delivered Family Therapy for Home Visited Young Mothers With Perinatal Depressive Symptoms: Quasi-Experimental Implementation-Effectiveness Hybrid Trial" (JMIR Ment Health 2018;5(4):e11513) by Cluxton-Keller et al, references 4 and 18 were duplicates.

The original reference 4 was as follows:

Duggan AK, Berlin LJ, Cassidy J, Burrell L, Tandon SD. Examining maternal depression and attachment insecurity as moderators of the impacts of home visiting for at-risk mothers and infants. J Consult Clin Psychol 2009 Aug;77(4):788-799.
It has been replaced by the following new reference:

Caldera D, Burrell L, Rodriguez K, Crowne SS, Rohde $C$, Duggan A. Impact of a statewide home visiting program on parenting and on child health and development. Child Abuse Negl 2007 Aug;31(8):829-52.

The correction will appear in the online version of the paper on the JMIR website on September 18, 2019, together with the publication of this correction notice. Because this was made after submission to PubMed, PubMed Central, and other full-text repositories, the corrected article also has been resubmitted to those repositories.

\section{Reference}

4. Caldera D, Burrell L, Rodriguez K, Crowne SS, Rohde C, Duggan A. Impact of a statewide home visiting program on parenting and on child health and development. Child Abuse Negl 2007 Aug;31(8):829-852. [doi:

10.1016/j.chiabu.2007.02.008] [Medline: 17822765] 
Edited by J Torous; this is a non-peer-reviewed article. Submitted 26.07.19; accepted 27.07.19; published 18.09.19.

Please cite as:

Cluxton-Keller F, Williams M, Buteau J, Donnelly CL, Stolte P, Monroe-Cassel M, Bruce ML

Reference Correction: Video-Delivered Family Therapy for Home Visited Young Mothers With Perinatal Depressive Symptoms:

Quasi-Experimental Implementation-Effectiveness Hybrid Trial

JMIR Ment Health 2019;6(9):e15661

URL: http://mental.jmir.org/2019/9/e15661/

doi: $10.2196 / 15661$

PMID: $\underline{31538950}$

CFallon Cluxton-Keller, Melony Williams, Jennifer Buteau, Craig L Donnelly, Patricia Stolte, Maggie Monroe-Cassel, Martha L Bruce. Originally published in JMIR Mental Health (http://mental.jmir.org), 18.09.2019. This is an open-access article distributed under the terms of the Creative Commons Attribution License (https://creativecommons.org/licenses/by/4.0/), which permits unrestricted use, distribution, and reproduction in any medium, provided the original work, first published in JMIR Mental Health, is properly cited. The complete bibliographic information, a link to the original publication on http://mental.jmir.org/, as well as this copyright and license information must be included. 